\title{
Implementación de un diseño piloto de bandejas de aireación para aguas, potencializado con microorganismos eficientes ${ }^{1}$
}

\author{
Implementation of a ventilation pilot design for \\ treatment water to efficient microorganisms
}

Implementação de um projeto-piloto de bandejas de ventilação para a água, com microrganismos eficientes

Recibido: enero de 2012

Aprobado: mayo de 2012
Rodrigo Fabián Calderón Muñoz ${ }^{2}$ Sandra del Pilar Forero Poveda ${ }^{3}$ Aide Suarez Cerquera ${ }^{4}$

\section{Resumen}

En este artículo se presenta la construcción e implementación de las mejores combinaciones de los parámetros de diseño de las bandejas de aireación y el metabolismo microbiano; el cual, es efectivo cuando entra en contacto con la materia orgánica, secretando sustancias beneficiosas como vitaminas, ácidos orgánicos, minerales y fundamentalmente sustancias antioxidantes que mejoranla calidad organoléptica del agua. Por lo general, el sistema de bandejas es utilizado para el tratamiento final de agua potable, en esta investigación se esta evidenciando el metabolismo microbiano como una alternativa para el tratamiento de aguas domésticas. Esto ha llevado a determinar la densidad poblacional de microorganismos aerobios por medio de preenriquecimientos y enriquecimientos, curvas de crecimiento bacteriano y, posiblemente al final, identificaciones bioquímicas, las cuales son capaces de metabolizar la contaminación doméstica de estas aguas. El prototipo en agua potable funciona a la perfección cumpliendo las características a medir en este tipo de aguas, el problema radica en la incorporación del inóculo de microorganismos eficientes en las bandejas para que actúen como un consorcio metabólico utilizando al oxígeno como fuente de energía, eliminando así los malos olores y aclarando el agua. Se esperaría que el material amortiguador de las bandejas, como el coque o el material que se escoja para este fin, sirva como inmovilizador de estos consorcios microbianos y ayude a evidenciarque el mantenimiento del prototipo se hace simultáneamente de forma física y biológica, es decir, en el momento que se lave el material amortiguador de las bandejas, así mismo se inocula otro consorcio de microorganismos eficientes. Según el estudio, la cantidad de microorganismos que se pueden adicionar en este prototipo es de $10 \mathrm{~mL}$ alcanzando a crear una biopelicula en la superficie del agua.

1 Artículo de investigación. Resultado de la investigación: Implementación de un diseño piloto de bandejas de aireación para aguas, potencializado con microorganismos eficientes; este trabajo fue financiado por la Universidad EAN.

2 Ph.D(c). Profesor de la Universidad EAN Bogotá, Colombia. Contacto:rcalderon.d@correo.ean.edu.co

3 Ing. M,Sc. Profesora de la Universidad EAN Bogotá, Colombia. Contacto:sandra.forero@correo.ean.edu.co

4 Química de la Universidad EAN Bogotá, Colombia. Contacto:asuarezc@correo.ean.edu.co 
Palabras clave: prototipo, organoléptico, aeración, microorganismos eficientes

\section{Abstract}

This study proposes to build and to enforce the best combination design parameters in aeration trays and microbial metabolism, which is effective when contacted with organic material throwing beneficial substances as vitamins, organic acids, minerals and above all things antioxidants substances improving organoleptic quality of water. Usually system trays is used to the final potable water treatment, in this case is showing microbial metabolism as a choice to the treatment in domestic sewage. This has been taken into account in determining population density of aerobic microorganisms through sowing and enriching the crop, bacterial growth curves and possibly at the end biochemical identifications, which are able metabolizing domestic sewage. The prototype in potable water works perfectly fulfilling all parameters to measure in this kind of water the problem lies in the incorporation of the inoculums to efficient organisms in the trays to act as a metabolic union using the oxygen as a source of energy, thus eliminating at least unpleasant odors, and clarifying the water. It is expected that the buffer material in the trays as the coke or the material that is eventually chosen for this purpose will serve as immobilizer of these microbial consortia and to help us to conclude that the maintenance of the prototype is being made simultaneously in physical form and biological, i.e. at the time to wash the buffer material in the trays as well same inoculated another consortium of microorganisms efficient. Apparently the amount of microorganisms that we can add in this prototype is $10 \mathrm{ml}$ reaching to create a biofilm on the surface of the water

Keywords: prototype, organoleptic, aeration, efficient microorganisms

\section{Resumo}

Neste estudo, propomos a construção e implantação das melhores combinações com parâmetros de projeto desses tabuleiros de arejamento o e metabolismo microbiano, o que é eficaz quando entra em contato com matéria orgânica secretando substâncias benéficas, como as vitaminas, ácidos orgânicos, sais minerais e antioxidantes essencialmente melhorar a qualidade organoléptica da água. Normalmente, o sistema bandeja é utilizada para tratamento de água potável, no caso, é demonstrando o metabolismo microbiano como alternativa para o tratamento de efluentes domésticos. Isso levou a determinar a densidade da população de microorganismos aeróbios por meio de preenriquecimentos e enriquecimentos, curvas de crescimento bacteriano e, possivelmente, o último identificação bioquímica, que são capazes de metabolizar poluição doméstica dessas águas. O protótipo na água potável funciona na perfeição que preencham as características para medir este tipo de água, o problema reside na incorporação do inóculo para organismos eficientes em bandejas, para agir como um consórcio metabólica com o oxigênio como fonte de energia, eliminando, assim, pelo menos odores desagradáveis, e clarificação da água. A expectativa é que o material de buffer em tabuleiros como o coque ou o material, que é escolhida para o efeito, irá 
servir como imobilizador destes consórcios microbianos e a ajudar-nos a concluir que a manutenção do protótipo está sendo feita simultaneamente de forma física e biológica, ou seja, o tempo para lavar o material de buffer nas bandejas bem mesmo inoculadas outro consórcio de microorganismos eficientes. Aparentemente, a quantidade de microorganismos que possamosadicionar a este protótipo é de $10 \mathrm{~mL}$ para criar um biofilme sobre a superfície da água.

Palavras-chave: protótipo, características organolépticas, aeração, microorganismos eficientes

\section{Introducción}

En la mayoría de áreas urbanas y rurales, el agua se trata en las instalaciones de tratamiento antes de distribuirla a los consumidores. Este método se conoce como tratamiento en la fuente, porque los contaminantesse eliminan en estas instalaciones antes de que se distribuya el agua. Si el agua no se trata antes de que se le de un uso en específico, ésta deberá ser tratada en el punto de uso para asegurar que la calidad del agua no causará enfermedades. Un método tradicional de tratamiento del agua ampliamente utilizado en todo el mundo consiste en hervir el agua para eliminar los contaminantes. El agua que se hierve plenamente de uno a tres minutos - un poco más en áreas montañosas- elimina la mayoría de patógenos.

Sin embargo, cabe mencionar la precaución siguiente:hervir el agua usualmente no es eficaz para la eliminación de contaminantes químicos. De hecho, la ebullición, por lo general, aumenta levemente la concentración de los mismos. El agua hervida corre además el riesgo de recontaminación durante el proceso de enfriamiento si no se la protege y almacena debidamente. Además, para hervir el agua se requiere una cantidad significativa de combustible, lo cual puede representar una carga financiera y ambiental.

A pesar de estas limitaciones, la ebullición es aún un tratamiento estándar cuando algún patógeno sea objeto de preocupación. En las últimas décadas, las agencias gubernamentales, organizaciones no gubernamentales y el sector privado han desarrollado nuevos e innovadores tratamientos de agua de uso doméstico para llevar soluciones sencillas de bajo costo y fáciles de usar a personas que deben dar tratamiento al agua en sus hogares.
Algunos de los sistemas domésticos para el tratamiento de agua utilizados más frecuentemente en los países en vías de desarrollo son la cloración, la filtración, la desinfección solar la filtración/cloración combinadas y la floculación cloración/combinadas.

\section{Problema de la investigación}

La ineficacia y falta de tratamiento de diferentes procesos de agua para su reúso, es el principal factor de investigación en este estudio, donde se prueba un prototipo de bandejas de aeración que normalmente logra buenos resultados a nivel de rangos químicos en la calidad del agua; pero que potencializa con microorganismos eficientes para incrementar los resultados de efectividad en el proceso.

\section{Justificación}

Uno de los inconvenientes del agua cruda es la poca presencia de oxígeno disuelto, esto se debe a que no hay un contacto intimo con los gases provenientes de la atmosfera, especialmente el oxígeno, que es de gran utilidad para mejorar el sabor, el olor y la oxidación del hierro, manganeso, sulfuro de hidrogeno $y$, hasta cierto punto, de materia orgánica que metabólicamente ayudan a los procesos de oxido-reducción. Siendo la ausencia de oxígeno disuelto (OD) en el agua un indicador de mala calidad. Además, la presencia de dióxido de carbono $\left(\mathrm{CO}_{2}\right)$ en el aguaocasiona una acción corrosiva del agua en tuberías y reacciona con los productos químicos empleados en el tratamiento de ablandamiento y en los procesos de separación del hierro y el sulfuro de hidrogeno, sin excluir los procesos fermentativos que ayuda a la proliferación de bacterias patógenas perjudiciales para los diferentes usos de este tipo de agua - agua doméstica-. 
La eficiencia en las bandejas de aireación se ve afectada por el espacio entre bandejas, temperatura del agua, carga hidráulica, espesor de la capa de soporte, orificios de las bandejas,entre otros. Es por esto que se propone realizar varias series de pruebas entre éstas con EMS, que se llevarán a cabo para desarrollar un modelo estadístico general para predecir el valor empírico del coeficiente cinético de la ecuación de Scott que, a su vez, puede ser utilizado en el diseño en las bandejas y determinará la eficiencia de los microorganismos en este método.

\section{Objetivos de la investigación}

\section{Objetivo general}

Implementar un diseño piloto de bandejas de aireación para aguas potencializado con microorganismos eficientes.

\section{Objetivos específicos}

- Establecer qué combinaciones de los parámetros de diseño son las adecuadas en la remoción de $\mathrm{CO}_{2}$, desorción de oxígeno con el uso de EMS.

- Desarrollo de un diseño con los parámetros establecidos en la construcción de las bandejas de aireación.

- Determinar una concentración óptima de EMS para el proceso de aireación.

\section{Reseña histórica}

\section{Clasificación convencional de tratamientos para aguas}

Antes de ver las tecnologías y los tratamientos que se utilizan para mejorar la calidad del agua in situ, conviene conocer la clasificación convencional de los distintos niveles de tratamiento que hay para el agua residual. El tratamiento primario es un simple tratamiento físico, una separación de los elementos sólidos que contiene el agua. Su objetivo es la eliminación de los sólidos en suspensión y los materiales flotantes, y de una parte de la materia orgánica del agua.
El tratamiento secundario tiene como objetivo la eliminación de la materia orgánica biodegradable —en suspensión o disuelta-, los sólidos en suspensión, los nutrientes — nitrógeno y fósforo-y la eliminación parcial de los microorganismos patógenos. Existen dos alternativas para el tratamiento secundario, los tratamientos químicos y los tratamientos biológicos. Los resultados de ambos son bastante similares en cuanto a los efectos, pero su mecanismo funcional es distinto. En el tratamiento químico se precisa la introducción de cantidades importantes de reactivos, un sistema de dosificación, y se necesita un equipo de personal cualificado que, de forma continua, modifique las dosificaciones para el correcto rendimiento del tratamiento. En cambio, en los sistemas biológicos la formación de flóculos, con peso suficiente para poder separarse de la masa de agua, se logra gracias a la acción enzimática y metabólica de los microorganismos que están en el agua residual(Hernández Muñoz, 2001).

Por último, los tratamientos terciarios, o avanzados, mejoran la calidad del efluente de salida de un tratamiento secundario, mejorando la calidad del agua en sólidos en suspensión, reducción de materia orgánica y de nutrientes. La desinfección del agua se incluye en esta etapa del tratamiento.

\section{Tratamientos físicos}

Los procesos físicos consiguen una substancial clarificación del agua y, además, reducen la carga orgánica. Sin embargo, los procesos físicos no son suficientes para garantizar la reducción de materia orgánica, nutrientes, surfactantes y tensoactivos que puede tener el agua residual doméstica. Por ello, los procesos físicos, por sí solos, no son recomendados para el tratamiento de las aguas grises y negras. Sin embargo, los procesos físicos como el filtro de arena o las membranas de filtración se pueden usar como postratamientos para propósitos de mejora del aspecto del agua.

El filtro de arena típico es una caja forrada de hormigón o de cloruro de polivinilo, llena de material arenoso. Estos filtros atrapan y absorben los contaminantes del agua residual cuando esta pasa a través de ellos. Reducen también el número de microorganismos patógenos causantes 
de enfermedadesque pueden estar presentes en el agua, pero no los elimina - es decir, no desinfectan-. El filtro de arena purifica el agua de tres formas:en primer lugar, las partículas se separan físicamente de las aguas que entran en el filtro por medio de la filtración. En la absorción química, los contaminantes se pegan a la superficie de la arena y al crecimiento biológico en la superficie de la arena.Finalmente, en la asimilación, los microbios aeróbicos consumen los nutrientes de las aguas.

Otro proceso físico empleado es la filtración por membranas. Las membranas usadas para la microfiltración tienen un tamaño de poro de 0,1 - 10 $\mu \mathrm{m}$. Estas membranas de microfiltración retienen todas las bacterias del efluente. Para la eliminación completa de los virus se requiere la ultrafiltración. Los poros de las membranas de ultrafiltración pueden retirar de los fluidos partículas de 0,001 - 0,1 $\mu \mathrm{m}$. En la ultrafiltración, el efluente es conducido al sistema por baja presión, donde membranas especiales de alta resistencia lo reciben para liberarlo de materiales de alto peso molecular y sólidos suspendidos. La ultrafiltración mediante membranas presenta una reducción muy importante de la DBO del agua, del orden del 98\% (Li, Wichmann, Otterpohl, 2009), así como de la cantidad de los nutrientes, fósforo y nitrógeno, aunque proporciona una limitada reducción de los orgánicos disueltos. El aspecto del agua es excelente, libre de sólidos en suspensión, con un bajo grado de turbidez y sin rastros de coliformes. Sin embargo, el gasto de energía y el ensuciamiento de la membrana son factores claves que limitan su uso por falta de viabilidad económica en muchos casos.

Por otro lado, los procesos de micro y ultrafiltración por membranas no son suficientes, por sí solos, para asegurar que la calidad del agua cumpla con los requisitos de salubridad para su reutilización, pues los residuos orgánicos restantes pueden provocar la proliferación de los patógenos en los sistemas de transporte y almacenamiento, así como limitar el efecto químico de la desinfección.

\section{Tratamientos químicos}

En comparación con los procesos físicos, los procesos químicos ofrecen resultados más satisfactorios en cuanto a reducción de materia orgánica y turbidez del agua, pero todavía no el suficiente como para hacer un uso sin restricción del flujo de agua resultante. Procesos como la electrocoagulación, seguida de una etapa de filtración y desinfección, son suficientes para llegar a una calidad admisible para usos como la descarga de los inodoros, si el flujo de entrada no está excesivamente contaminado.

La electrocoagulación consiste en añadir a las aguas iones metálicos coagulantes mediante el uso de electrodos. Estos iones coagulan los contaminantes que hay en el agua, de modo similar a los coagulantes químicos como el alumbre o el cloruro férrico, permitiendo que los precipitados sean más fácilmente eliminados mediante sedimentación. Los procesos químicos pueden eliminar eficientemente los sólidos en suspensión, la materia orgánica y los surfactantes en flujos de aguas grises poco contaminados. Por lo tanto, no son adecuados para tratar aguas negras. En general, los procesos químicos son muy poco usuales en los sistemas satélite de tratamiento de aguas in situ.

\section{Tratamientos biológicos}

El tratamiento biológico es la pieza central de los tratamientos de aguas residuales domésticas aguas grises y aguas negras-. Los procesos aeróbicos biológicos son capaces de conseguir una gran mejora de la turbidez y de la materia orgánica. La pobre eliminación de la materia orgánica y surfactantes hacen que los procesos anaeróbicos no sean adecuados para el tratamiento de las aguas grises, aunque se contaría con la ventaja de producir biogás. Después del proceso aeróbico, la mayoría de las substancias orgánicas biodegradables son eliminadas y, consecuentemente, la proliferación de los microorganismos y los problemas de olor son evitados, haciendo el efluente más apto para poder ser almacenado por periodos más largos de tiempo. Sin embargo, se obtiene una escasa eliminación de microorganismos, sólidos en suspensión y turbidez, por lo que se requiere una etapa final de filtración y desinfección para conseguir una calidad que permite el uso urbano del agua tratada.

Los tratamientos biológicos suelen venir precedidos de una etapa física, como el uso de un tanque 
de sedimentación o una fosa séptica, para que se depositen los sólidos y se eliminen aceites y grasas. Los tratamientos más extendidos para plantas de tratamiento satélite son el Rotating Biological Contactor (RBC), el Sequencing Batch Reactor (SBR), y el Membrane Bioreactor (MBR).

El RBC consiste en una serie de grandes discos paralelos, llamados biodiscos constituidos de poliestireno rígido atóxico, que rotan en torno un eje común, de manera que medio disco está sumergido en el líquido, mientras que el otro está expuesto al aire y se oxigena. Los discos se mueven muy lentamente (entre 1 y 2 min-1) a través de las aguas residuales. Rotating Biological Contactor (Asano, 2007).

En unos diez o doce días, los microorganismos forman una flora bacteriana en la superficie de los discos. La comunidad de microorganismos absorbe directamente la mayor cantidad de materia orgánica durante la fase de inmersión en el agua residual, y el oxígeno necesario durante la fase de emersión. La capa de flora bacteriana que se adhiere a las placas, al alcanzar un espesor de unos 4 o $5 \mathrm{~mm}$, se despega del biodisco en forma de copos fácilmente sedimentables.

Sus ventajas son la sencillez de gestión y mantenimiento, que sólo incluye tareas de limpieza periódica del depósito y los biodiscos, y mantenimiento del motor. Por otro lado, el consumo de energía es muy bajo, y la eficiencia del tratamiento biológico es muy alta. Su inconveniente es el tamaño y la compacidad del sistema que lo hacen menos apto que el MBR y el SBR para alojarse en espacios reducidos. Esto representa una clara ventaja para los otros dos sistemas en las aplicaciones de plantas satélite de reciclaje in situ de aguas residuales domésticas. Sin embargo, el RBC también es una opción muy extendida, cuya eficacia ha sido constatada a lo largo de los años.

El SBR es una variación del proceso de lodos activados que minimiza requerimientos de espacio al realizar diversas etapas del tratamiento en un mismo depósito. En el SBR el agua residual es almacenada en un depósito pulmón, o en la cámara de aireación hasta que un volumen suficiente (batch) es recolectado, momento en el que el proceso empieza. El batch de agua residual es tratado por los microorganismos aeróbicos (lodos activados) y aireado durante el periodo de tratamiento. Después de que la reacción se completa, se detiene la aireación y la agitación, con lo que las bacterias floculadas y otras partículas sólidas sedimentan. El estrato depurado se descarga de la cámara, y entra el siguiente batch de agua residual. El llenado, reacción, descarga es un ciclo que se repite continuamente (Asano, 2007; disponible en: http://www.soliclima.com)

La principal ventaja es la compacidad del sistema, que permite hacer el tratamiento primario, el tratamiento biológico y el tratamiento de desinfección, en un mismo tanque. Esto lo hace una opción compacta e idónea para un gran número de aplicaciones en plantas satélite de tratamiento. Sus inconvenientes son que requieren válvulas adicionales, bombas, y controles adicionales comparados con otros sistemas. El tiempo de residencia hidráulico es de unas $8-14$ h para la depuración de las aguas.

El MBR combina el tratamiento biológico con un sistema de membranas - en el rango de la ultrafiltración-, para reducir la cantidad de materia orgánica del agua y eliminar los sólidos en suspensión. Las membranas sustituyen la sedimentación y la filtración, para separar la biomasa del agua tratada. Combinando el reactor biológico con un sistema de filtración por membranas, se reducen los requerimientos de espacio y se reducen los costes de tratamiento.

El MBR se considera como una tecnología innovadora en el ámbito del tratamiento de aguas grises debido a la estabilidad del proceso y su eficacia para eliminar patógenos. Los MBR están empezando a ser considerados como una alternativa muy atractiva para los edificios urbanos de viviendas. El agua tratada por la membrana tiene muy poca turbidez. Los sistemas de membrana consumen más energía ya que suelen trabajar a presiones que superan los 2,0 bar (Al-Jayyousi, 2003).

Los MBR son particularmente adecuados para las aplicaciones satélite por su compacidad y su capacidad para ubicarse en espacios pequeños. Las ventajas del MBR son que las instalaciones ocupan 
menos espacio, se obtiene un efluente de agua de mucha calidad, se reduce la producción de lodos y es un sistema de fácil manejo. Sin embargo, presentan problemas en el mantenimiento y la limpieza de las membranas. La suciedad de la membrana incrementa además su resistencia hidráulica, con la demanda extra de energía por parte del sistema que eso conlleva. El pretratamiento siempre es requerido para prevenir la colmatación de los poros de la membrana. Otro inconveniente del MBR es su elevado precio, que lo hace económicamente inviable para pequeñas comunidades de vecinos (Asano, 2007).

\section{Tratamientos de desinfección}

El agua tiene una serie de enfermedades asociadas a patógenos que pueden contener, bacterias, protozoos y virus. Si las aguas no han sido desinfectadas antes de ser almacenadas, y se ha reducido de esta forma el crecimiento patógeno, durante el almacenamiento el número de patógenos crecerá significativamente.

\section{Microorganismos eficientes}

La tecnología de los microorganismos eficientes, fue desarrollada por Teruo Higa, profesor de horticultura de la Universidad de Ryukyus en Okinawa, Japón. A comienzos de los años sesenta, el profesor Higa comenzó la búsqueda de una alternativa que remplazará los fertilizantes y plaguicidas sintéticos y en los últimos años ha incursionado en su uso en procesos de compostaje, tratamiento de aguas residuales, ganadería y para el uso en la limpieza del hogar.

Estudiando las funciones individuales de diferentes microorganismos, Higa encontró que el éxito de su efecto potenciador estaba en su mezcla; por esto se dice que los microorganismos eficientes (ME) trabajan en sinergia, ya que la suma de los tres tiene mayor efecto que cada uno por separado. Los ME están compuesto por bacterias fotosintéticas o fototrópicas (Rhodopseudomonas spp), bacterias ácido lácticas (Lactobacillus spp) y levaduras (Saccharomyces spp).

\section{Diseño metodológico}

\section{Tipos de investigación}

Exploratoria: Conduce al planteamiento de una hipótesis donde la función de la investigación descubre bases de información que permiten la posterior realización de investigaciones descriptivas y crea, en otros investigadores, el interés por el estudio de un nuevo tema o problema;concluyendo con la formulación de una hipótesis.

\section{Fases de la investigación}

\section{Diseño del prototipo}

Las bandejas de aireación para el prototipo son de plástico, tienen unas perforaciones sobre ellas, y además tienen una inclinación para asegurar la distribución del agua cayendo sobre las otras en similares condiciones, las cuales son variables de diseño importantes. Tienen unos 0.60, 0.75 y 0.95 $\mathrm{cm}$ aproximadamente (La Motta, 1996).

- Se colocará medio grueso del material en las bandejas. El material a utilizar será esferas de material cerámico; sugeridas por Scott (2000).

- El medio grueso utilizado tiene un diámetro de $5-15 \mathrm{~cm}$ de diámetro, que mejora la eficiencia en el intercambio de gases y la distribución del agua (Scott, 2000).

- El espesor del medio grueso es una variable a experimentar en las bandejas, serán tres variables: 15, 23 y $30 \mathrm{~cm}$. (Romero, 2000).

- El área de cada bandejas es aproximadamente es de $60^{\star} 60 \mathrm{~cm}$. Sugeridas por Romero(2000), y cuatro bandejas de aireación (Romero, 2000).

- En los momentos de ensayo se tuvieron las bandejas de aireación en un lugar donde corrió el viento, ya que esto mejoró la eficiencia del proceso (La Motta, 1996).

- La carga hidráulica fue otro parámetro a evaluar, son tres variables: $2.5,3.5$ y $4.5 \mathrm{~L} / \mathrm{s}$. (La Motta, 1996).

- La distancia vertical de las bandejas es un parámetro importante, pues entre más tiempo el agua tenga contacto directo con la atmósfera, 
mayor será su aireación. Esta fue de $70 \mathrm{~cm}$, sugeridas por Scott (2000).

- Se insertarán paredes de madera para prevenir la perdida de agua a causa de lasgotas que salpicany la influencia del viento.

En un segundo ensayo se hizo el mismo procedimiento para agua doméstica, introduciendo un inóculo de ME en la bandeja 1, a los cuales ya se les comprobó su actividad por medio de siembras masivas con sus respectivas diluciones y se evaluaronlos mismos análisis,como:

- Pruebas de oxígeno disuelto: se realizó con el método multiparamétrico de medición in situ. Es importante en tantoque su medición favoreció el análisis de los resultados pues no hubó transporte de muestras que puedaalterar el valor.

- Pruebas de $\mathrm{CO}_{2}$ : se midieron basados en el estándar métodos, cesión $4500-\mathrm{CO}_{2}$ A. Para determinar el $\mathrm{CO}_{2}$ libre en el agua potable, se determinó con el método de titulación con el indicador de fenolftaleína (awwa and apha). Este método es el más rápido y es satisfactorio para pruebas de campo. Los reactivos a utilizar: reactivo de hidróxido de sodio y fenolftaleína.

- Prueba de la demanda biológica de oxígeno:esta se medió basadosen el estándar métodos, cesión 5220-D. La prueba de la DBO es un procedimiento experimental, tipo bioensayo, que midió el oxígeno requerido por los organismos en sus procesos metabólicos al consumir la materia orgánica presente en las aguas residuales o naturales. Las condiciones estándar del ensayo incluyeron incubación en la oscuridad a $20^{\circ} \mathrm{C}$ por un tiempo determinado, generalmente cinco días. Las condiciones naturales de temperatura, población biológica, movimiento del agua, luz solar y la concentración de oxígeno no pueden ser reproducidas en el laboratorio. Los resultados obtenidos se tomaron en cuenta para lograr una adecuada interpretación.

- Prueba microbiológica: se hicieron siembras aeróbicas masivas y selectivas en agar nutritivo para la identificación de densidad poblacional microbiana interactuando en el agua del modelo.

\section{Recuento en placa de ME}

Esta técnica consistió en colocar, en un medio de cultivo adecuado, un volumen determinado de muestra. Cada una de las células aisladas se dieron lugar después de la incubación correspondiente. El sistema fue fácil de utilizar en el caso de células aisladas. Se llevo acabo sembrando en superficie - extendiendo un volumen de muestra sobre el medio de cultivo sólido-. Para que el sistema de recuento en placa tuviera validez estadística, fue necesario contar entre 30 y 300 colonias, con objeto de disminuir el error de la medida, y para tener en éste estudio la suficiente densidad poblacional microbiana en el proceso de potencialización para el tratamiento de aguas.

\section{Ensayos}

Primero se determinó el origen de la muestra de agua. Para agua potable,lamuestra correspondió a la obtenida de las llaves del laboratorio de ciencias básicas,y la de agua residual doméstica se recolectóen cocinas de domicilios. Se vertieron en el prototipo desde la bandeja 2 para agua potable y la bandeja 1 para agua residual doméstica, donde la aplicabilidad de los diferentes tipos de aireadores y su dosificación, se determinaron controlando el tiempo de aireación y la eficiencia de remoción; esta última como el porcentaje entre la variable química a remover en el efluente y el afluente de los dos tipos de aguas.

\section{Ensayo para agua doméstica}

Diagnóstico inicial de oxigeno disuelto, DQO y DBO para el agua doméstica con multiparámetro y técnicas anteriormente descritas.

Se introduce el agua doméstica desde la bandeja 1 para que interactué con el inóculo de ME inoculado en el coqué durante cinco días, donde empiezan a bajar las características organolépticas. 
Diagnóstico final de oxigeno disuelto, DQO y DBO para el agua doméstica con multiparámetro y técnicas anteriormente descritas. Al cumplir características similares al agua potable, se abre la llave de la bandeja 1 después de los cinco días, para que actúe normalmente el proceso como se describe en el ensayo para agua potable.

\section{Ensayo para agua potable}

Diagnóstico inicial de oxigeno disuelto, DQO y DBO para el agua potable con multiparámetro y técnicas anteriormente descritas.

Se introduce el agua potable en la bandeja 2 la cual, por decantación gravitacional y su inclinación, cae a la bandeja 3 donde encontrará un lecho filtrador con coqué que aumentará la posibilidad de sorción de características adversas a la potabilización, donde, también por acción gravitacional e inclinación en un tiempo determinado, cayó a la bandeja 4 la cual se encarga de la recepción final de todo el proceso de tratamiento del agua. Y de donde se recolecta la muestra final de análisis para su comparación y conclusión frente a la efectividad del sistema.

\section{Prueba microbiológica final}

Se realizó un enriquecimiento selectivo descrito anteriormente, para determinar la densidad poblacional bacteriana que posiblemente se encuentra en el final del tratamiento de la misma, lo cual indujo a posibles usos del agua tratada.

\section{Desinfección}

Se realizó la desinfección exclusivamente si el agua, que se trabajaría en este estudio, sería para consumo humano, el cual no es uno de los objetivos, pero según la efectividad del prototipo se pudo manejar concentraciones bajas de cloro para este fin.

\section{Resultados y discusión}

\section{Prototipo}

La construcción del prototipo evidencia que es un pretratamiento, como parte de los procesos que buscan una calidad del agua cruda y residual doméstica apropiada a las necesidades del usuario y en el reúso de las mismas, que comprendeun cierto número de operaciones mecánicas, físicas y químicas, que tienen por objeto separar del agua la mayor cantidad posible de materias que, por su naturaleza o tamaño, puedan ser motivo de problemas en el tratamiento. Motivo que dio origen a un diseño combinado.

\section{Prototipo para agua potable}

En la aireación por bandejas se puso en contacto el agua cruda con el aire, esto con el propósito de modificar la concentración de sustancias volátiles contenidas en ella, la aireación se recomienda en los siguientes casos:

- Transferir oxígeno al agua y aumentar con ello el oxígeno disuelto.

- Disminuir la concentración de dióxido de carbono $\left(\mathrm{CO}_{2}\right)$.

- Remover compuestos orgánicos volátiles (COV).

La aplicabilidad de las bandejas aireadoras y su dosificación fueron determinadas a través de ensayos, controladas en el tiempo de aireación y la eficiencia de remoción; esta última como el porcentaje entre la variable química a remover en la cantidad de agua que fue de 4 litros en 6 horas.

Las bandejas de coqué consistieron en una serie de superficies de 0.15 a $0.2 \mathrm{~m}^{2}$ (por cada $10 \mathrm{~m}^{3}$ de capacidad) con un lecho de coquéde espesor de 0.015 a 0.03 $\mathrm{m}$. conformado por partículas de $0.02 \mathrm{a} 0.05 \mathrm{~m}$. sobre las cuales se vierte el agua cruda a una carga máxima de $10 \mathrm{~m}^{3} / \mathrm{m}^{2}$ por hora, de forma que se genere una capa de aproximadamente $0.015 \mathrm{~m}$. Lo que allí se genera es una caída del agua de bandeja a bandeja y por ende una aireación con la añadida capacidad del carbón para absorber y adsorber químicos. 

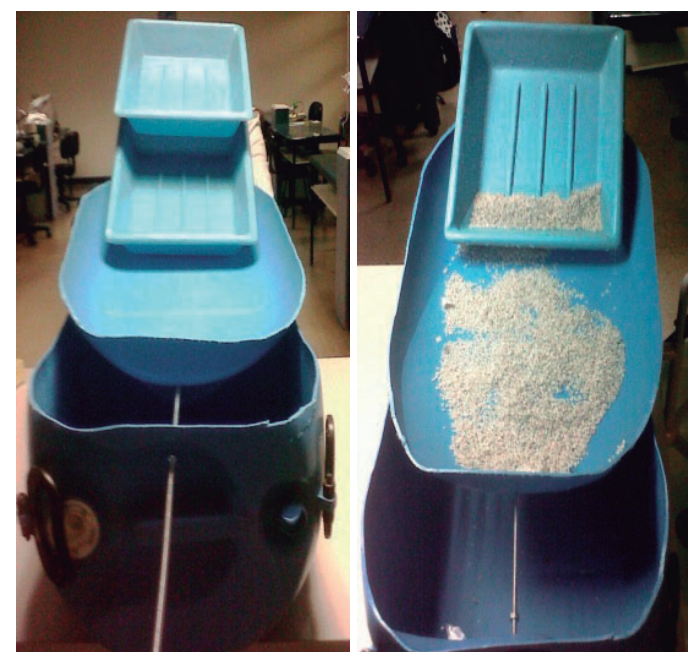

Figura 1. y Figura 2. Prototipo completo y prototipo en funcionamiento para agua potable

Fuente: elaboración propia

En estos resultados se encuentra que: entre los ensayos antes del tratamiento y después del tratamiento no hay ninguna diferencia significativa, caso contrario si la comparación se hace solamente frente al antes y después del tratamiento. Lo anterior se presenta pues los valores de DBO, DQO y SST evidencian una diferencia significativa al $60 \%$ de efectividad del prototipo, dado que, a pesar los datos no corresponden a un riesgo de contaminación del agua potable, sí lleva a que el proceso del prototipo efectúeuna acción eliminadora de las características proporcionalmente a la acción biológica de los compuestos químicos en el agua potable.

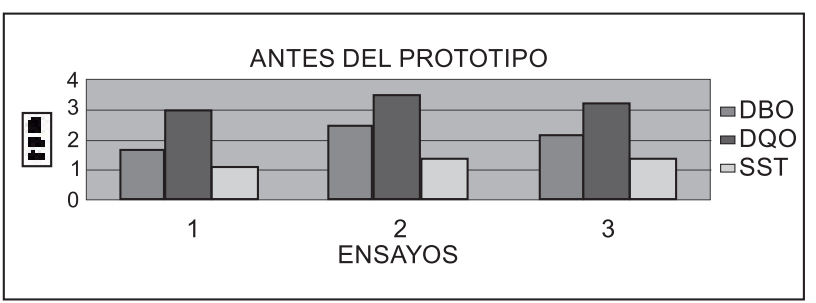

Gráfica 1. Diferencia de las características de los ensayos antes del prototipo.

Fuente: elaboración propia

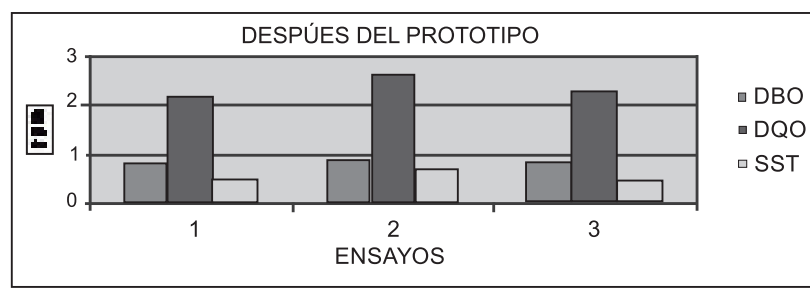

Gráfica 2. Diferencia de las características de los ensayos después del prototipo.

Fuente: elaboración propia

La efectividad del sistema de bandejas de aireación, según los ensayos, demuestra que la diferencia del porcentaje hace óptimo el proceso así:

Para el ensayo 1 DBO el prototipo es óptimo en un $53 \%$, para el DQO en un $27 \%$ y para SST en un $55 \%$.

Para el ensayo $2 \mathrm{DBO}$ el prototipo es óptimo en un $64 \%$, para el DQO en un $26 \%$ y para SST en un $50 \%$.

Para el ensayo 3 DBO el prototipo es óptimo en un $60 \%$, para el DQO en un $29 \%$ y para SST en un $65 \%$.

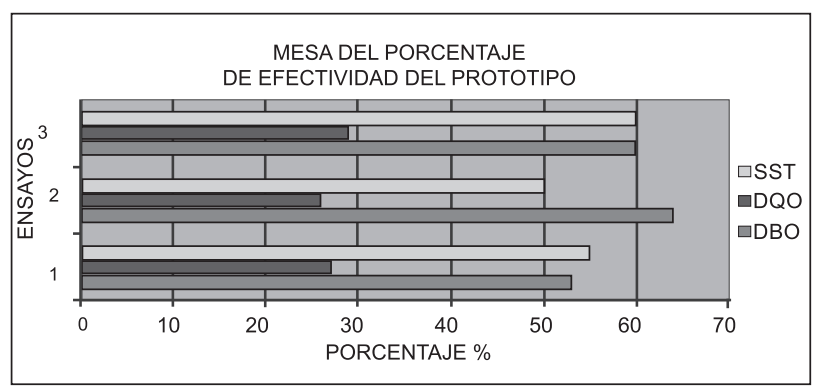

Gráfica 3. Porcentaje de efectividad del prototipo por ensayo.

Fuente: elaboración propia

Los resultados obtenidos evidencian una eficiencia significativa, teniendo en cuenta que los parámetros medidos en el inicio de las pruebas no inducen a presentar rangos por fuera de la norma frente a las características del agua potable. Pero síconcluye la efectividad del proceso para bajar los índices que puedan afectar esas características, por lo que se estipula un proceso para dicho fin. 


\section{Prototipo para agua residual doméstica}

En este segundo paso del proceso se adicionóuna bandeja (1) al inicio del prototipo con el fin de modificar características que sobrepasan los límites permitidos del agua para su reúso. Esta bandeja se encarga de potencializar las reacciones bioquímicas para disminuir los rangos de DBO, DQO y SST, y en secuencia realizanun proceso de aireación igual al paso anterior como sí fuera agua potable. Este ejercicio innovador se realizó con ME, los cuales efectuaron dichas reacciones bajando los niveles de contaminación por medio de sus metabolismos después de su estandarización dentro del prototipo en diluciones óptimas para complemento del proceso de tratamiento.

\section{Densidad poblacional y concentración del inoculo de ME}

Se realizaron tres secuencias de recuento en placa en la primera dilución 1:10 donde se obtuvo un promedio aproximado de $44 \mathrm{X} 106 \mathrm{Ufc} / \mathrm{ml}$.

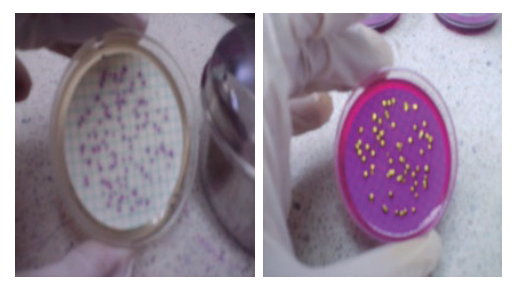

Figura 3. Recuento en placa

de microorganismos eficientes.

Fuente: elaboración propia

Este resultado evidencia que los ME no han perdido su efectividad potencial en el sustrato de conservación, y tienen una acción efectiva bajo las características y parámetros in vitro. También se evidencianunos crecimientos superiores a 300 colonias por placas contadas. Esto asegura que bajo la proporción 1:10 en un amortiguador como el coqué, los ME pueden crear una película en menos de 12 horas, ya que la media de crecimiento, según los recuentos,inducen a que hay triplicidad en la cinética de crecimiento de los microorganismos y puede invadir el área de la bandeja en muy corto tiempo, por lo que disminuye, a su vez, el tiempo de acción bioquímica con el agua a tratar de 15 a 5 días, tiempo de almacenamiento del agua doméstica a tratar en la bandeja 1 del prototipo.

\section{Prototipo para agua residual doméstica con ME}

La aplicabilidad de las bandejas aireadoras y su dosificación, fueron determinadas a través de ensayos, controlados en este caso por el tiempo de aireación, el metabolismo de los microorganismos eficientes y la eficiencia de remoción; esta última como el porcentaje entre la variable química a remover en la cantidad de agua que fue de cuatrolitros en cincodías.

La primera bandeja consistió en el almacenamiento y manutención de los microorganismos eficientes con coqué, vertiendo el agua residual domestica por cincodías, tiempo donde se encontró la mayor efectividad metabólica de los microorganismos, bajando los niveles de contaminación. Después de los cinco días, se realizó el procedimiento normal expuesto anteriormente en el tratamiento del agua potable aclarando que esta adición es para encontrar unas características óptimas para el reúso del agua residual doméstica a tratar.
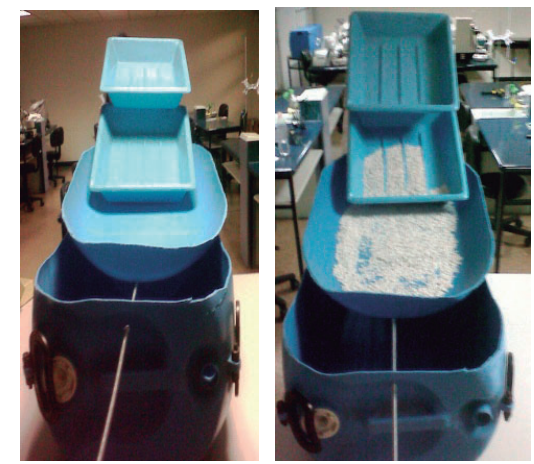

Figura 4. y Figura 5. Prototipo completo y prototipo en funcionamiento para agua residual doméstica

Fuente: elaboración propia

Estos resultados muestran que la comparación entre los ensayos, antes del tratamiento, durante (ME) y después del tratamiento, respectivamente, no muestraunadiferencia significativa de forma individual; pasa lo contrario si la comparación se hace solamente frente al antes, el durante y después del tratamiento,ya que los valores de DBO, DQO y SST evidencian una diferencia significativa porcentual de efectividad del prototipo; este caso es de suma importancia, ya que los datos obtenidos sobrepasan lo límites de contaminación respecto al $\mathrm{DBO}$ y, muy cercanosa ellos, el DQO y SST; obligando al prototipo a incrementar su potencia con ME, eliminando 
esas características que descategorizan al agua residual doméstica para su reúso, como en la actualidad se puede hacer en la agricultura, en la limpieza, en la industria de enfriamiento,entre otras.

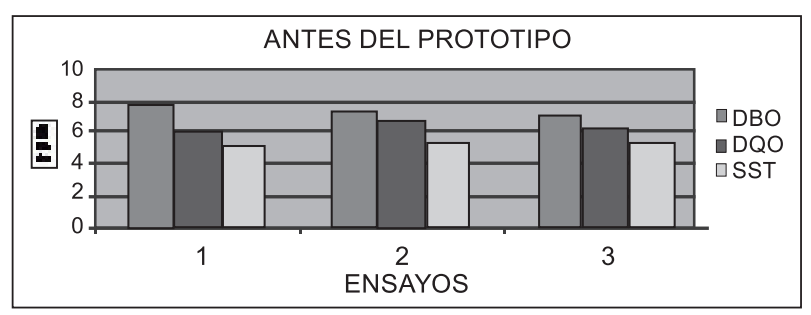

Gráfica 4. Diferencia de las características de los ensayos antes del prototipo.

Fuente: elaboración propia

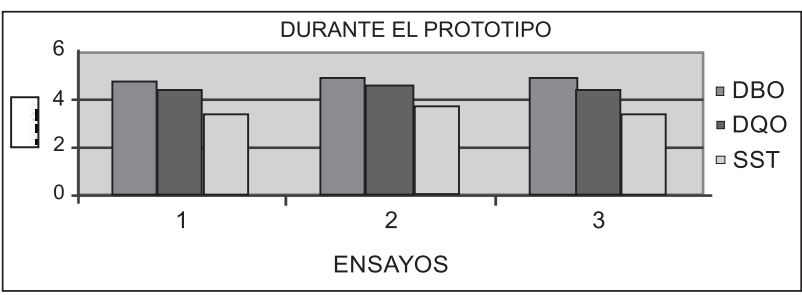

Gráfica 5. Diferencia de las características de los ensayos durante el prototipo (ME).

Fuente: elaboración propia

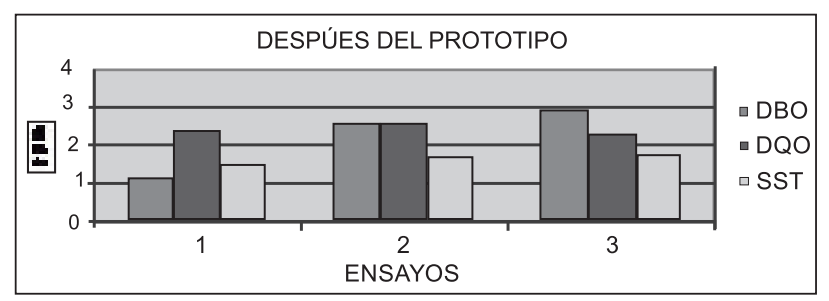

Gráfica 6. Diferencia de las características de los ensayos después del prototipo.

Fuente: elaboración propia

La efectividad del sistema de bandejas de aireación potencializada con ME, según los ensayos, demuestra que la diferencia del porcentaje hace óptimo el proceso de la siguiente manera:

Para el ensayo $1 \mathrm{DBO}$ antes-durante el prototipo es óptimo en un $38 \%$, para el DQO en un $27 \%$ y para SST en un $31 \%$. Para el ensayol DBO durante-después el prototipo es óptimo en un $42 \%$, para el DQO en un $45 \%$ y para SST en un $57 \%$.
Para el ensayo 2 DBO antes-durante el prototipo es óptimo en un 35\%, para el DQO en un 29\% y para SST en un $31 \%$. Para el ensayo2 DBO durante-después el prototipo es óptimo en un $47 \%$, para el DQO en un $43 \%$ y para SST en un $54 \%$.

Para el ensayo $3 \mathrm{DBO}$ antes-durante el prototipo es óptimo en un 35\%, para el DQO en un 34\% y para SST en un 35\%. Para el ensayo 3 DBO durante-después el prototipo es óptimo en un $41 \%$, para el DQO en un $47 \%$ y para SST en un $49 \%$.

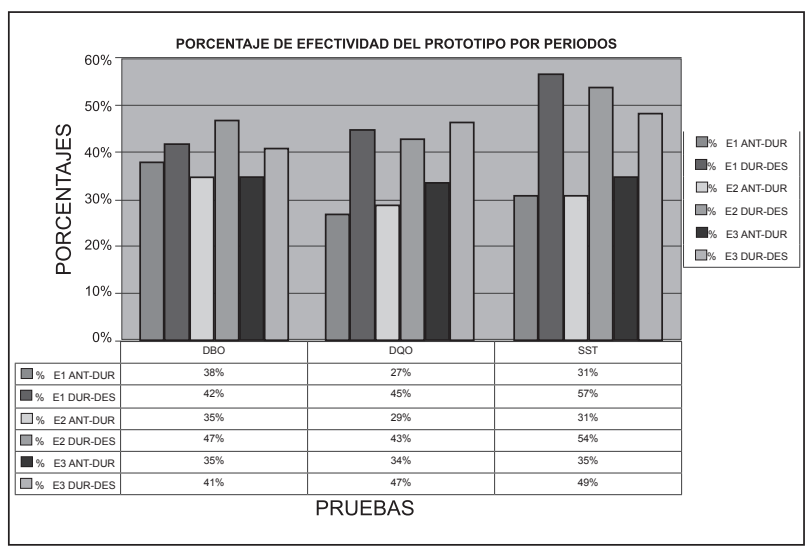

Gráfica 7. Porcentaje de efectividad del prototipo por ensayo.

Fuente: elaboración propia

Los resultados obtenidos evidencian una eficiencia significativa, teniendo en cuenta que los parámetros medidos en el inicio de las pruebas inducen a presentar rangos por fuera de la norma, como lo es un agua residual doméstica, exceptuando los parámetros de DQO. Pero sí concluye la efectividad del proceso para bajar los índices que puedan afectar esas características, por lo que se estipula que es un proceso óptimo para tratar los índices de DBO y SST y mantener más bajos los de DQO.

En síntesis, la comparación de las dos pruebas del prototipo para el tratamiento de agua potable y agua residual doméstica, arroja un resultado primordial, ya que esta alternativa de forma complementaria muestra que, para DBO, la efectividad es en un rango del $35 \%$ al $64 \%$, para DQO, la efectividad es dentro de un rango del $27 \%$ al $47 \%$ y para SST la efectividad es en un rango del $31 \%$ al $65 \%$. 
Resultado que muestra que la alternativa de bandejas de aireación potencializada con ME, es una herramienta innovadora para bajar los índices de posibles contaminaciones en agua potable y agua residual doméstica, para su uso y reúso respectivamente.

\section{Diagnóstico microbiológico final del prototipo para agua residual doméstica}

El promedio del resultado fue $07 \mathrm{X} 100 \mathrm{Ufc} / \mathrm{ml}$ donde se evidencia la efectividad de retención que tiene el prototipo para darle un reúso al agua así:

\begin{tabular}{|l|}
\hline \multicolumn{1}{|c|}{ Uso } \\
\hline $\begin{array}{l}\text { Residenciales: riego de jardines, descarga de aparatos sani- } \\
\text { tarios, sistemas de calefacción y refrigeración de aire y otros } \\
\text { usos domésticos. }\end{array}$ \\
\hline $\begin{array}{l}\text { Servicios urbanos: riego de zonas verdes urbanas —parques, } \\
\text { campos deportivos—baldeo de calles; sistemas contra incendios; } \\
\text { fuentes y láminas ornamentales. Lavado industrial de vehículos. }\end{array}$ \\
\hline $\begin{array}{l}\text { Cultivos de invernadero:riego de cultivos para consumo en } \\
\text { crudo. Frutales regados por aspersión. }\end{array}$ \\
\hline $\begin{array}{l}\text { Riego de pastos para consumo de animales productores de leche } \\
\text { o carne. Riego de cultivos destinados a industrias conserveras y } \\
\text { productos que no se consuman crudos. Riego de frutales excepto } \\
\text { por aspersión. Acuicultura }\end{array}$ \\
\hline $\begin{array}{l}\text { Riego de cultivos industriales, viveros, forrajes ensilados, } \\
\text { cereales, semillas oleaginosas y cultivo de flores ornamentales } \\
\text { excepto por aspersión }\end{array}$ \\
\hline $\begin{array}{l}\text { Refrigeración industrial. } \\
\text { Queda prohibida la reutilización de aguas depuradas en los } \\
\text { circuitos de refrigeración industrial de la industria alimentaria } \\
\text { y similar. }\end{array}$ \\
\hline Riego de campos de golf \\
\hline $\begin{array}{l}\text { Estanques, láminas de agua y caudales circulantes ornamen- } \\
\text { tales, en los que está impedido el acceso del público al agua. }\end{array}$ \\
\hline $\begin{array}{l}\text { Riego de bosques, zonas verdes y de otro tipo no accesibles al } \\
\text { público. Silvicultura. }\end{array}$ \\
\hline Recarga deacuiferos por percolación localizada a través del terreno. \\
\hline Recarga de acuíferos por inyección directa \\
\hline
\end{tabular}

Tabla 1. Posibles usos del agua residual doméstica tratada en el prototipo de aeriación.

Fuente: elaboración propia

\section{Desinfección}

La desinfección del agua para este tipo de tratamiento puede ser muy eficaz cuando la inactivación química de los contaminantes microbiológicos, en agua natural o no tratada, es normal,siendo uno de los pasos finales de la purificación para la reducción de microorganismos patógenos en el agua. En este caso se tendría en cuenta el tipo de reúso del agua para tal fin, por lo que no sería necesario según los resultados obtenidos en el estudio.

\section{Diseño general del prototipo en un equipo de filtración}

Según el funcionamiento del prototipo se obtuvo un diseño que lo convierte en un equipo tecnificado para el tratamiento de aguas.

Se obtienen dimensiones para que, en un próximo proyecto, se construya y se ubique en el Laboratorio de Ciencias Básicas de la Universidad EAN, para las prácticas académicas, la investigación y la posible prestación de servicios.

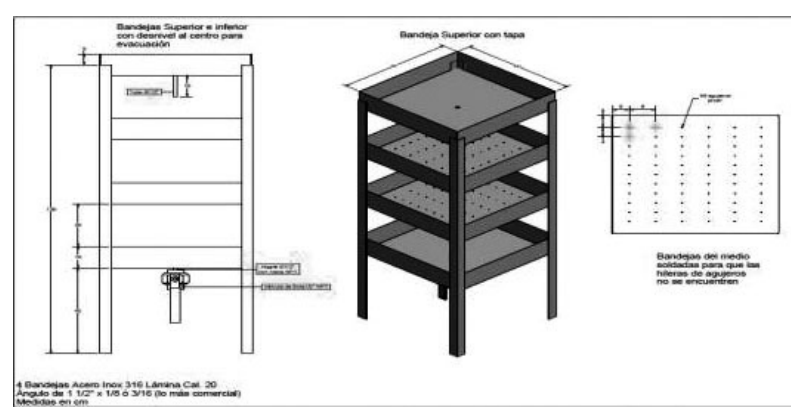

Figura 6. Detalle de diseño del equipo de filtración a partir del prototipo.

Fuente: elaboración propia

\section{Conclusiones}

Por el trabajo realizado en la investigación, se encontraron las condiciones óptimas para el funcionamiento de un prototipo que incrementa la concentración de oxígeno a las velocidades requeridas para garantizar que el oxígeno no limite la metabolización de la materia orgánica presente.

Se evidencia claramente una muy buena intervención por parte de los ME con el prototipo de bandejas de aireación, ya que tienen un buen crecimiento bajo las condiciones invitro, se relacionaron muy bien con el amortiguador (coqué), y se identifica su acción potencializadora en las características 
organolépticas del agua a tratar (color y olor) y la metabolización de compuestos contaminantes.

Se evidenció la efectividad del prototipo en rango aproximado del $60 \%$ al $70 \%$ para disminuir las concentraciones de DBO, DQO y SST, en los factores de la calidad de agua potable y para encontrar el reúso del agua residual doméstica en la agricultura, en la industria de enfriamiento donde ciertos parámetros permisibles se cumplen en pro de la legislación para la misma.

El diseño de un prototipo de bandejas de aireación para el tratamiento de aguas, demuestra la factibilidad en la academía, pues ayuda a entender y relacionar los diferentes fenómenos físicos combinados con los bioquímicos, encontrando los diferentes usos del agua después de haber pasado por este tipo de tratamiento.

El estudio en general abre las puertas para posibles proyectos que fortalezcan la función del prototipo, en beneficio del problema de la contaminación de aguas, que a su vez induce a su tecnificación como equipo dentro del Laboratorio de Ciencias Básicas para la prestación de servicios y desarrollo de investigaciones.

\section{Referencias}

Al-Jayyousi, O. R. (2003). "Greywater reuse: towards sustainable water management”. Desalination, (156): 181-192.

Asano, T.; Burton, F.; Leverenz, H.; Tsuchihashi, R. and Tchobanoglous, G. (2007). Water Reuse: Issues, Technologies, and Applications. New York: Metcalf \& Eddy. Editorial McGraw-Hill.

Christova-Boala, D.; Edenb, R. E. and McFarlane, S. (1995). "An investigation into greywaterreuse for urban residential properties". Desalination, (106):391 - 397.

Equaris. (2011). Empresa estadounidense de tratamiento de aguas residuales. Acceso: 15 de enero de 2011. Disponible en: http://www. equaris.com
Eriksson, E.; Andersen, H. R.; Madsen, T. S. and Ledin, A. (2009). "Greywater pollutionvariability and loadings". Ecological engineering,(35): $661-669$.

Eriksson, E.; Auffarth, K.; Henze, M. and Ledin, A. (2002). "Characteristics of grey wastewater". Urban Water, (4):85 - 104.

Hernández M., A. (2001). Depuración y desinfección de aguas residuales. Colegio de Ingenieros de Caminos, Canales y Puertos (UPM). Madrid: Colección Senior.

HOG. (2010). Empresa australiana de tanques para aprovechamiento de las aguas pluviales. Acceso: 14 de septiembre de 2010. Disponible: http:// rainwaterhog.com

Li, F.; Wichmann, K. and Otterpohl, R. (2009). "Review of the technological approaches for greywater treatment and reuses". Science of the Total Environment, (407): 3439 - 3449.

Marcadiferencia. (2010). Venta de productos para la protección del medio ambiente. Acceso: 20 de mayo de 2010. Disponible en: http://www. marcadiferencia.com

March, J. G.;Gual, M. y Orozco, F. (2004). "Experiences on greywater re-use for toilet flushingin a hotel (Mallorca Island, Spain)". Desalination, (164): 241-247.

Multicapas. (2010). Empresa distribuidora de tuberías para fontanería y saneamiento. Acceso: 21 de junio del 2010. Disponible en: http://www. multicapas.com

Multishower. (2010). Tienda de elementos ahorradores de agua. Acceso: 15 de junio de 2010. Disponible: http://www.multishower.org

Nolde, E. (2006)."Possibilities of rainwater utilisation in densely populated areas includingprecipitation runoffs from traffic surfaces". Desalination, (215): 1-11.

Rose, J.B.; Sun, G.S.; Gerba, C. P. and Singlair, N.A. (1991). "Microbial quality and persistence ofenteric pathogens in greywater from various household sources". Water research, 25(1): 37-42. 